\title{
Association of genetic and psychological factors with persistent pain after cosmetic thoracic
} surgery

\author{
Violeta Dimova ${ }^{1-3}$ \\ Jörn Lötsch ${ }^{3}$ \\ Kathrin Hühne ${ }^{4}$ \\ Andreas Winterpacht ${ }^{4}$ \\ Michael Heesen ${ }^{5}$ \\ Andreas Parthum ${ }^{1,2}$ \\ Peter G Weber ${ }^{6}$ \\ Roman Carbon ${ }^{6}$ \\ Norbert Griessinger ${ }^{2}$ \\ Reinhard Sittl ${ }^{2}$ \\ Stefan Lautenbacher ${ }^{1}$ \\ 'Physiological Psychology, Otto- \\ Friedrich University Bamberg, \\ ${ }^{2}$ Pain Center, Friedrich-Alexander \\ University Erlangen, ${ }^{3}$ Institute of \\ Clinical Pharmacology, Goethe \\ University, Frankfurt am Main, \\ ${ }^{4}$ Department of Human Genetics, \\ Friedrich-Alexander University \\ Erlangen, Germany; ${ }^{5}$ Department of \\ Anaesthesia, Kantonsspital Baden, \\ Baden, Switzerland; ' $D$ epartment of \\ Pediatric Surgery, Friedrich-Alexander \\ University Erlangen, Germany
}

Correspondence: Violeta Dimova Institute of Clinical Pharmacology, Goethe University, Theodor Stern Kai 7, 60590 Frankfurt am Main, Germany Tel $+4969630 I 87818$ Fax +4969630I 7636

Emaildimova@med.uni-frankfurt.de
This article was published in the following Dove Press journal: Journal of Pain Research

27 November 2015

Number of times this article has been viewed

Abstract: The genetic control of pain has been repeatedly demonstrated in human association studies. In the present study, we assessed the relative contribution of 16 single nucleotide polymorphisms in pain-related genes, such as cathechol-O-methyl transferase gene (COMT), fatty acid amino hydrolase gene $(F A A H)$, transient receptor potential cation channel, subfamily V, member 1 gene (TRPV1), and $\delta$-opioid receptor gene (OPRD1), for postsurgical pain chronification. Ninety preoperatively pain-free male patients were assigned to good or poor outcome groups according to their intensity or disability score assessed at 1 week, 3 months, 6 months, and 1 year after funnel chest correction. The genetic effects were compared with those of two psychological predictors, the attentional bias toward positive words (dot-probe task) and the self-reported pain vigilance (Pain Vigilance and Awareness Questionnaire [PVAQ]), which were already shown to be the best predictors for pain intensity and disability at 6 months after surgery in the same sample, respectively. Cox regression analyses revealed no significant effects of any of the genetic predictors up to the end point of survival time at 1 year after surgery. Adding the genetics to the prediction by the attentional bias to positive words for pain intensity and the PVAQ for pain disability, again no significant additional explanation could be gained by the genetic predictors. In contrast, the preoperative PVAQ score was also, in the present enlarged sample, a meaningful predictor for lasting pain disability after surgery. Effect size measures suggested some genetic variables, for example, the polymorphism rs $1800587 \mathrm{G}>\mathrm{A}$ in the interleukin 1 alpha gene $(I L 1 A)$ and the COMT haplotype rs4646312T $>\mathrm{C} / \mathrm{rs} 165722 \mathrm{~T}>\mathrm{C} /$ rs6269A $>\mathrm{G} / \mathrm{rs} 4633 \mathrm{~T}>\mathrm{C} / \mathrm{rs} 4818 \mathrm{C}>\mathrm{G} / \mathrm{rs} 4680 \mathrm{~A}>\mathrm{G}$, as possible relevant modulators of longterm postsurgical pain outcome. A comparison between pathophysiologically different predictor groups appears to be helpful in identifying clinically relevant predictors of chronic pain.

Keywords: genetics, COMT, OPRM1, postoperative pain, PVAQ

\section{Introduction}

Despite good analgesic treatment, a major proportion of patients undergoing surgery still develops chronic pain. ${ }^{1}$ Pathophysiological mechanisms underlying chronic postsurgical pain comprising inflammation, immune response to injury and wounds, and peripheral sensitization causing neuropathic pain and central sensitization are under genetic regulation. ${ }^{2}$ Thus, a gene-based approach appears very promising for explaining why some patients develop chronic pain after surgery and others not.

The genetics of pain have been impressively demonstrated in recent years by extensive research in laboratory animals ${ }^{3,4}$ and in human association studies. ${ }^{5-7}$ Over 400 genes have been recognized as pain modulators. ${ }^{8}$ Polymorphisms in genes such as cathechol- $O$-methyl transferase gene (COMT), $\mu$-opioid receptor gene (OPRM1), 
GTP cyclohydrolase 1 gene $(G C H 1)$, human leukocyte antigen (HLA) gene complex, 5-hydroxytryptamine (serotonin) receptor 2 a gene $(H T R 2 A)$, interleukin 1 alpha gene (IL1A), interleukin 1 beta gene $(I L 1 B)$, interleukin 1 receptor antagonist gene $(I L I R N)$, and transient receptor potential cation channel, subfamily $\mathrm{V}$, member 1 gene (TRPV1) are among the most often investigated candidate genes in pain genetic research associated with clinical as well as experimental pain. ${ }^{9}$ Concerning postoperative pain, associations were mostly shown for cytokine genes, the COMT, and OPRM1 genes. ${ }^{10-14}$ The genetic basis for the transition from acute to chronic postoperative pain is still unknown.

In the present study, we assessed the relative role of genotyping information for explaining pain continuation up to 1 year after funnel chest operation in a slightly enlarged sample of male pain-free patients already reported. ${ }^{15}$ Given the lack of genetic associations with chronic postthoracotomy pain, 31 single nucleotide polymorphisms (SNPs) were chosen from human association studies published until August 2009 (Table 1 for related references). Candidate genes were selected 1) to involve mechanisms of inflammation and wound healing to cover the obvious pathophysiological processes assumed to play a role in pain after surgery and 2) to include the most broadly investigated genes in pain research such as COMT, OPRM1, GCH1, and fatty acid amino hydrolase gene $(F A A H)$, which are involved in the modulation of pain perception and cognitive processing. The genetic predictors were tested for their predictive power using a comparison to the best psychological predictors identified in a previous study in this clinical sample. ${ }^{15}$ Two pain-related psychological variables, namely, the attentional bias toward words of positive valence assessed in a dot-probe task and the selfreported pain vigilance (Pain Vigilance and Awareness Questionnaire [PVAQ]), were found to be the strongest predictors for chronic pain and disability after surgery, respectively. ${ }^{15}$ Thus, these two psychological predictors were used as a frame of comparison for the genetic predictors. Specifically, the genetic predictors were tested for their power to predict the time course of pain intensity and pain disability up to 1 year after surgery. Subsequently, they were added to the prediction of the respective best psychological predictor for establishing their relative contribution for postoperative pain and disability up to 1 year after surgery.

\section{Materials and methods Patients}

Ninety men (mean \pm standard deviation [SD] $23.5 \pm 4.6$ years) undergoing a cosmetic correction of funnel chest malformation were selected among consecutively admitted inpatients at the Department of Pediatric Surgery of the University of Erlangen. Eighty percent of the patients participated also in a previous study by Lautenbacher et al. ${ }^{15}$ Because of the high rate of men undergoing this type of surgical correction, only male patients participated. Inclusion criteria were 1) age between 14 years and 35 years, 2) informed written consent to data acquisition and an additional separate informed written consent to blood sampling and genotyping, 3) no contraindication for the surgical procedure, and 4) postoperative analgesic treatment via the patient-controlled epidural analgesia (PCEA). Exclusion criteria were 1) concurrent acute or chronic pain conditions, 2) previous major surgical interventions (minor surgical interventions, such as tonsillectomies or dental procedures, were allowed), 3) strong levels of discomfort due to functional limitations because of the chest malformation, and 4) past and current psychological disorders as diagnosed by a German standardized psychological screening for International Statistical Classification of Diseases and Related Health Problems 10th edition, and Diagnostic and Statistical Manual of Mental Disorders, IV edition, the Mini-DIPS. ${ }^{16}$

All patients underwent a thoracic surgery for cosmetic correction of congenital chest malformations named "funnel chest". The surgical procedure is known as the Erlangen technique of funnel chest correction. ${ }^{17}$ For moving the sternum in the desired position, first the sternum is freed through an interior incision and then it is mobilized by freeing of the xiphisternum. After correction of the chest, the chest wall is stabilized with a lightweight transsternal metal implant. The metal implant is removed $\sim 1$ year after the surgery. The patients received a standardized analgesia during and after surgery via a commonly applied and recommended thoracic PCEA. Before the induction of general anesthesia for surgery, an epidural catheter was inserted through the interspinous space at Th6/ Th7 or Th7/Th8. Postoperative PCEA was provided using a standard PCA pump. The pump was set to deliver $0.2 \%$ ropivacaine plus $1.0 \mu \mathrm{g} / \mathrm{mL}$ sufentanil at a basal rate of $6-8 \mathrm{~mL} / \mathrm{h}$. Patients could additionally request a bolus dose of $3 \mathrm{~mL}$ every 30 minutes by pressing a trigger button. Repeated pressing of the trigger button did not provide more than one bolus per 30 minutes. The PCEA catheter was usually removed 2-3 days after surgery. As rescue analgesics on demand, the nonopioids, S-ketoprofen, diclofenac, dipyrone, and paracetamol, and the opioids, buprenorphine or piritramide, were available.

The study protocol was approved by the Ethics Committee of the Medical Faculty of the University of ErlangenNürnberg. All patients gave informed written consent. In 
Table I Single nucleotide polymorphisms (SNPs, database number) and haplotypes in candidate pain genes with corresponding observed minor allele frequencies (MAF) used for selection of the genetic predictors

\begin{tabular}{|c|c|c|c|c|c|c|}
\hline Gene & Function & $\begin{array}{l}\text { SNP database } \\
\text { number (minor } \\
\text { allele right) }\end{array}$ & Reference & MAF of SNP (\%) & Haplotype & $\begin{array}{l}\text { MAF of } \\
\text { haplotype(\%) }\end{array}$ \\
\hline$B D K R B I$ & $\begin{array}{l}\text { Receptor for bradykinin, } \\
\text { inflammation, burns, shocks, etc }\end{array}$ & rs4905475 G>C & 58 & 11.5 & & \\
\hline \multirow[t]{2}{*}{$C A R D 15=N O D 2$} & Immune response & rs2066844 C>T & 59 & 3.9 & & \\
\hline & & rs2066845 G>C & & 1.6 & & \\
\hline \multirow[t]{6}{*}{ СОMT } & Metabolization of catecholamines, & rs46463 I $2 \mathrm{~T}>\mathrm{Ca}^{\mathrm{a}}$ & $51,57,60,61$ & 37.4 & $\mathbf{C} / \mathbf{C} / \mathbf{G} / \mathbf{C} / \mathbf{G} / \mathbf{G}$ & 36.1 \\
\hline & neurotransmission & rsl65722 T>Ca & & 43.4 & $\mathrm{C} / \mathrm{C} / \mathrm{G} / \mathrm{C} / \mathrm{C} / \mathrm{G}$ & 0.6 \\
\hline & & rs6269 A $>\mathbf{G}^{a}$ & & 36.8 & $\mathrm{C} / \mathrm{C} / \mathrm{A} / \mathrm{C} / \mathrm{G} / \mathrm{G}$ & 0.6 \\
\hline & & rs4633 T>Ca & & 43.4 & $\mathrm{~T} / \mathrm{C} / \mathrm{G} / \mathrm{C} / \mathrm{C} / \mathrm{G}$ & 0.6 \\
\hline & & rs48 $18 \mathrm{C}>\mathbf{G}^{\mathrm{a}}$ & & 36.3 & $\mathrm{~T} / \mathrm{C} / \mathrm{A} / \mathrm{C} / \mathrm{C} / \mathrm{G}$ & 6.1 \\
\hline & & rs4680 A $>\mathbf{G}^{a}$ & & 43.4 & $\mathbf{T} / \mathbf{T} / \mathbf{A} / \mathbf{T} / \mathbf{C} / \mathbf{A}$ & 56.1 \\
\hline \multirow[t]{3}{*}{ FAAH } & Degradation of fatty acid amide & rs9328I6 G >A & 57 & 27.5 & & \\
\hline & family of endogenous signaling lipids & rs4|4|964 C >T & & 40.7 & & \\
\hline & & rs2295633 G $>A$ & & 39.0 & & \\
\hline \multirow[t]{3}{*}{$\mathrm{GCHI}$} & Biosynthesis of biogenic amines & rs8007267 C > T & 48,62 & 15.9 & & \\
\hline & and nitric oxide & $\mathrm{rs} 378364 \mid \mathrm{T}>\mathrm{A}$ & & 18.1 & & \\
\hline & & rsl0483639 G>C & & 17.0 & & \\
\hline ILIA & Inflammation, immunity & rs|800587 G>A & 49 & 35.7 & & \\
\hline ILIB & Inflammation & $\mathrm{rs}|| 43634 \mathrm{G}>\mathrm{A}$ & $59,63,64$ & 28.3 & & \\
\hline ILIRN & Inhibition of inflammation & rs $2234677 \mathrm{G}>\mathrm{A}$ & 5,63 & 23.1 & & \\
\hline IL23R & Immune response & rsII $209026 \mathrm{G}>\mathrm{A}$ & 65 & 4.4 & & \\
\hline MMP2 & $\begin{array}{l}\text { Angiogenesis, tissue repair, } \\
\text { inflammation }\end{array}$ & rs $243865 \mathrm{C}>\mathrm{T}$ & 66 & 20.9 & & \\
\hline \multirow[t]{5}{*}{$N K I R$} & Metabolism of substance-P & rs6715729 G>A & 20 & 47.3 & & \\
\hline & & rs735668 C $>A^{b}$ & & 47.3 & T/A & 35.6 \\
\hline & & rs674lo29 G $>\mathbf{T}^{\mathrm{b}}$ & & 36.3 & $\mathrm{~T} / \mathrm{C}$ & I.I \\
\hline & & & & & $\mathbf{G} / \mathbf{A}$ & 11.7 \\
\hline & & & & & $\mathbf{G} / \mathbf{C}$ & 51.7 \\
\hline \multirow[t]{2}{*}{ NR3C2 } & Receptor for mineralocorticoids & rs5522 T>C & 21 & 14.3 & & \\
\hline & and glucocorticoids & rs207095 I C $>\mathbf{G}$ & & 47.8 & & \\
\hline OPRDI & Mediation of encephalin effects & rs22349I8 T $>C$ & 54,57 & 39.0 & & \\
\hline OPRMI & Mediation of endorphin effects & $\mathrm{rs}|79997| \mathrm{A}>\mathrm{G}$ & 5,67 & 12.6 & & \\
\hline TGFBI & Regulation processes in cells & rs| 800469 G $>$ A & 68 & 33.0 & & \\
\hline \multirow[t]{2}{*}{ TRPAI } & Detection of noxious stimuli, cold & rsl I $988795 \mathrm{C}>\mathrm{T}$ & 57 & 31.3 & & \\
\hline & perception & $\mathrm{rs} \mid 3255063 \mathrm{~A}>\mathrm{T}$ & & 4.4 & & \\
\hline TRPVI & $\begin{array}{l}\text { Detection of noxious chemical and } \\
\text { thermal stimuli }\end{array}$ & rs8065080 T $>C$ & $54,57,69$ & 37.4 & & \\
\hline
\end{tabular}

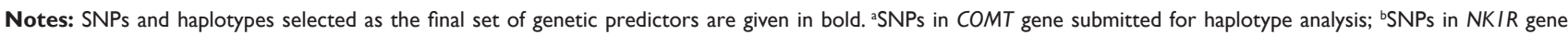
submitted for haplotype analysis.

Abbreviations: $B D K R B I$, bradykinin receptor $\mathrm{BI}$ gene; $C A R D$ I5, nucleotide-binding oligomerization domain containing 2 gene; COMT, cathechol-O-methyl transferase gene; $F A A H$, fatty acid amino hydrolase gene; GCHI, GTP cyclohydrolase I gene; ILIA, interleukin I alpha gene; ILIB, interleukin I beta gene; IL23R, interleukin 23 receptor gene; ILIRN, interleukin I receptor antagonist gene; MMP2, matrix metallopeptidase 2 gene; NKIR, tachykinin receptor I gene; NR3C2, nuclear receptor, subfamily 3, group C, member 2 gene; OPRDI, $\delta$-opioid receptor gene; OPRMI, $\mu$-opioid receptor gene; TGFBI, transforming growth factor, beta I gene; TRPAI, transient receptor potential cation channel, subfamily A, member I gene; TRPVI, transient receptor potential cation channel, subfamily $\mathrm{V}$, member I gene.

case of not having attained legal age (18 years), informed written consent was obtained from their parents and written assent from the subject. All participating patients received financial compensation.

\section{Data acquisition}

One preoperative session on the day before surgery and four postoperative sessions at 1 week, $\sim 3$ months, 6 months, and 1 year after surgery were conducted. The sessions took place mostly in the afternoon. In the preoperative session 1 day before surgery, among other preoperative predictors (questionnaires, experimental pain sensitivity) a self-report questionnaire of pain hypervigilance (PVAQ) ${ }^{18}$ and a dotprobe task measuring attentional biases toward pain-related, social threat, and positive words were assessed. Data on preoperative predictors have already been published. ${ }^{15,19}$ 
In the postoperative sessions, self-report ratings of pain intensity and pain disability were obtained. Blood samples were collected at the Pain Centre of the University Hospital Erlangen during the preoperative preparation of the patients for surgery. For patients already included in the behavioral assessment before the beginning of the genetic study, blood sampling was conducted 1 year postsurgery during the preparation of the patients for the surgical removal of the metal implant.

\section{Genetic predictors}

The candidate genes were selected 1) to involve mechanisms of inflammation and wound healing underlying pathophysiological processes involved in pain after surgery and 2) to include the most frequently investigated genes in pain research such as COMT, OPRM1, GCH1, and FAAH. Specifically, SNPs were derived from a PubMed database search for human association studies published until August 2009 using free text combinations of the termini: pain, nociception, pain disease, single nucleotide polymorphism, polymorphism, genetic polymorphism, human genetics study, and human association study (Table 1). For variants in the tachykinin 1 receptor gene $(N K 1 R)$ and the mineralocorticoid receptor gene, nuclear receptor, subfamily 3 , group $\mathrm{C}$, member 2 gene (NR3C2), no human pain association studies were found up to this time point. Substance $P$ and mineralocorticoids such as cortisol play a crucial role in inflammatory and stress-induced response to pain; thus, variants in the $N K 1 R$ gene were derived from a study on alcohol dependence ${ }^{20}$ and for the $N R 3 C 2$ gene from a study on cortisol responses following dexamethasone application. ${ }^{21} \mathrm{~A}$ set of 31 SNPs in 17 genes were finally selected for the study.

Following this selection, we performed a posteriori verification of the functional focus of the selected genes on postoperative inflammatory and wound healing processes. For this purpose, the 17 genes were analyzed in a systems-genetics context. Specifically, the biological roles in which a given set of genes are involved can be obtained from publicly available knowledge databases. The gold standard in this field is the Gene Ontology (GO; http://www.geneontology.org/), ${ }^{22}$ where the major biological processes of the genes, respectively, gene products, are described by a controlled vocabulary (GO terms). ${ }^{23}$ An overview on GO as well as on concepts such as "ontology" in computer science can be found in Thomas et al. ${ }^{24}$ The functions of the 17 selected pain genes were analyzed by means of an overrepresentation analysis (ORA) ${ }^{25}$ using the web-based GeneTrail tool (http://genetrail.bioinf. uni-sb.de/). ${ }^{26}$ Other applications of similar GO-based analysis were already reported in biomedicine. ${ }^{27,28}$ For the present analysis, a reference set of 410 known pain genes and their annotations to GO terms was used for comparison. In particular, all GO terms associated with the available reference list of pain genes, $n=410,{ }^{29}$ were compared with the occurrence of the terms among the subset of $n=17$ genes from the present study. ORA was done with parameter $P$-value threshold, $t_{\mathrm{p}}=0.05$, and a false discovery rate $\alpha$ correction for multiple testing. ${ }^{30}$ From this analysis, the biological processes have emerged, in which the $n=17$ genes were particularly engaged among the reference set of $n=410$ pain genes (Figure $S 1$, original ORA tree from the GeneTrial results output). Figure S1 displays the 21 significant GO terms annotated at the given ORA parameters to the $n=17$ genes. Among them, the seven most significant terms (Table S1) pointed to biological processes of "response to chemical stimuli", "response to stress", "immune system response", "immune response", "cognition", "inflammatory response", and "sensory perception" (detailed definitions of the GO terms available at the AmiGo search tool for the GO at http://amigo.geneontology. $\left.\underline{\operatorname{org}^{\beta 1}}{ }^{31}\right)$. This supported our selection of genes as covering key biological processes expected during the development of pain after surgical intervention.

\section{Genotyping analysis}

For genotyping of the patients, genomic DNA was extracted from peripheral blood using a Flexigene AGF 3000 technology (Qiagen NV, Venlo, the Netherlands) on an automated Autogenflex 3000 isolator (Autogen, Holliston, MA, USA) according to the protocols supplied by the provider. For genotyping the TaqMan ${ }^{\circledR}$, OpenArray ${ }^{\circledR}$ Genotyping Systems (Thermo Fisher Scientific, Waltham, MA, USA) was used, which is a high-performance, high-throughput technology based on real-time polymerase chain reaction. The plates used for the OpenArray ${ }^{\circledR}$ assay were composed of 48 subarrays, with 64 nanowells that were prefilled with custom-made assays (Thermo Fisher Scientific) for the genotyping of 32 SNPs in total. After addition of $100 \mathrm{ng}$ genomic DNA and reaction mix to the corresponding wells, the arrays were placed in a Thermocycler BIORAD DNA Engine Peltier Thermal Cycler for fragment amplification. Arrays were scanned on the OpenArray NT imager, and genotypes were called using the OpenAray SNP Genotyping Analysis software. Whenever assay design or the genotyping assay failed, SNPs were genotyped by polymerase chain reaction amplification (primer sequences available on request) and subsequent Sanger sequencing of both strands on an automated capillary sequencer ABI3730 (Thermo Fisher Scientific). The resulting sequences were 
then analyzed with the Sequencer DNA Sequence Analysis software (Gene Codes Corporation, Ann Arbor, USA).

\section{Psychological factors}

For determining the predictive strength of the genetic predictors, two psychological predictors were used for comparison, namely, the preoperatively measured pain vigilance and the attentional bias to positive words assessed via a dot-probe task. These were chosen as best possible predictors according to our previously published findings in this sample. ${ }^{15}$ In this study, preoperative predictors encompassing pain-related and general psychological predictors (pain catastrophizing, pain anxiety and hypervigilance, depression, state anxiety, somatization, attentional bias for emotionally loaded words), psychophysical predictors (cold and heat pain thresholds, heat pain summation), and cortisol reactivity were tested for their power to explain chronic pain and disability up to 6 months after surgery. The attentional bias for positive words and the self-reported pain vigilance (PVAQ) proved to be the best preoperative predictors for persisting pain and disability for both 3 months and 6 months after surgery, respectively. ${ }^{15}$ Thus, these two psychological predictors were chosen for comparison and are described in the following.

The $\mathrm{PVAQ}^{18}$ has been developed as a comprehensive measure of attention to pain and validated for the use in chronic pain and nonclinical samples. It consists of 16 items that are rated on a six-point scale and assess awareness, vigilance, preoccupation, and observation of pain. For the present study, the questionnaire was translated into German using a standard "forward-backward" procedure. Only if the resulting backward English version was very similar to the original version according to the evaluation of an English native speaker, translation accuracy was considered as sufficient. The original English version of the questionnaire has been shown to have good internal consistency (Cronbach's $\alpha=0.86)$ and test-retest reliability $(\mathrm{rtt}=0.80) .{ }^{18}$ The German version used in this study showed sufficient internal consistency (Cronbach's $\alpha=0.85$ ) in a previous study. ${ }^{32}$ The present German version of the PVAQ was repeatedly successfully used in clinical and experimental studies. ${ }^{15,19,32,33}$ For further analyses, the sum score of the PVAQ was used as a parameter of interest for predicting pain disability.

The selective attention task used in the present study was based on the dot-probe task described by Keogh et al. ${ }^{34}$ It has been used in our laboratory in different clinical and experimental studies. ${ }^{15,19,32,35}$ It contains three emotional word categories: pain-related (eg, stechend (Ger.)/stinging), social threat (eg, beschämt (Ger.)/ashamed), and positive words (eg, glücklich (Ger.)/lucky). These words are paired with neutral words (Anstrich (Ger.)/paintwork); neutral-neutral word pairs served as filler items.

Following Keogh et al, ${ }^{34}$ a fixation cross in the center of a computer screen was presented for $500 \mathrm{~ms}$. Subsequently, two words, that is, a neutral one paired with an emotional one, were presented concurrently, one below and one above the center. After another $500 \mathrm{~ms}$, the words disappeared and a dot appeared at the location of one of the two words. Patients were required to indicate by pressing a key as quickly as possible where the dot had appeared (below or above). After 20 practice trials, patients had to complete 128 experimental trials (32 trials per word-pair category) presented in random order. The reaction times in response to the dot were assessed. To assess selective attentional processes related to each of the emotional word categories, bias indices were calculated according to the formula by Keogh et al: $:^{34}$ Bias score $=(($ eudl - eldl $)+($ eldu - eudu $)) / 2$, where the letters mean $\mathrm{e}=$ emotional word, $\mathrm{d}=\mathrm{dot}, \mathrm{u}=$ upper position, and $\mathrm{l}=$ lower position. A positive score indicates an attentional preference for the location of the emotional word, whereas a negative score may suggest attentional avoidance.

\section{Assessment of postoperative pain}

At each of the postoperative time points, patients were asked to rate the average intensity of their pain on an eleven-point numerical rating scale (NRS), labeled with the verbal anchors "no pain" (0) and "strongest pain imaginable" (10). At 1 week postsurgery, pain ratings were acquired for the preceding week, and at 3 months, 6 months, and 1 year postsurgery for the preceding 4 weeks. Patients were also asked to complete the pain disability index (PDI $)^{36}$ as a common measure of pain disability. It consists of seven items assessing the degree to which pain interferes with functioning across different classes of activities, such as social activities, recreation activities, and professional life activities. Each item could be scored between 0 (no interference) and 10 (total interference). Our previous study in this sample showed enough variance in data regarding the two outcome measures after 3 months postsurgery, a time frame which is commonly defined as chronic pain.

\section{Statistics}

\section{Preprocessing of genetic data}

For verifying a random genetic sample, the distribution of homozygous and heterozygous carriers of alleles was tested for agreement with the Hardy-Weinberg equilibrium ${ }^{37}$ using $\chi^{2}$ goodness-of-fit tests (Haploview software Version 4.2 $2^{38}$ ). For subsequent analyses, only SNPs were used that fulfilled 
the following criteria: 1) genotype groups with $\mathrm{n}>10$ patients as prerequisite for parametric group statistics and 2) observed minor allelic frequency (MAF) of $\geq 10 \%$ as a prerequisite for sufficient distribution of the genetic variants in the present sample. The resulting set of genetic predictors comprised 16 SNPs in eight genes (Table 1), which is roughly half of the originally targeted 17 genes. These SNPs were then included in the order of their chromosome positions in in silico haploblock detection using 95\% confidence bounds on $\mathrm{D}^{\prime 39}$ and in a subsequent haplotype analysis ( $\left.\mathrm{PHASE}^{40,41}\right)$.

\section{Classification of postoperative outcome}

For separating patients with poor outcome after surgery from patients who have almost optimally recovered, a classification of postoperative outcome was computed. Patients were assigned to a "high" (NRS: 3-10) or "low" (NRS: 0-2) pain intensity group and to a "high" (PDI: 9-70) or "low" (PDI: 0-9) pain disability group for each of the postoperative time points according to their pain intensity and disability scores. The protocol followed the classification used in Lautenbacher et al. ${ }^{15}$ The cutoff score of two points for pain intensity was set according to the findings of Farrar et al, ${ }^{42}$ suggesting that relevant clinical changes on the numerical rating scale are indicated by differences of at least two scale units. The cut off for pain disability was set at a score of 8, indicating the minimum level of clinically relevant pain-related disability as suggested by Dillmann et al. $^{43}$

Additionally, time-dependent changes in pain intensity and disability over the postoperative time course were tested using nonparametric repeated-measures approach (Friedman's test) because the scores of both measures were not normally distributed $(D(90)=[0.150-0.309], P<0.001)$ with the only exception of the pain disability scores at 1 week postsurgery. Post hoc analyses for differences between time points were run using Wilcoxon signed-rank test.

\section{Prediction of postoperative outcome}

The power of the genetic predictors for explaining the postoperative 1-year time course of pain-associated clinical parameters was assessed by means of Cox regression analysis. The proportional hazard function allows assessing the probability (hazard ratio [HR]) to reach an event of interest, adjusted for the influencing factors, during a defined period of time termed survival time. ${ }^{44}$ In the present study, the event of interest was a postoperative outcome of low pain intensity or low pain disability at 1 year after surgery (criterion variables). The genetic and psychological variables were defined as covariates (predictors) influencing the course of postoperative outcome. Predictors were entered in the prediction model at a threshold significance level of $\alpha<0.05$ (corresponding to a critical $\chi^{2}=3.842, d f=1$ ) and were removed at $\alpha<0.10$.

First, the influence of the genetic variables on postoperative outcome was tested. Separate stepwise Cox regression analyses (stepwise forward procedure) were conducted for pain intensity and disability including the final set of genetic variables (SNPs and haplotypes) as predictive factors for reaching an outcome of low pain intensity and disability. Each SNP or haplotype was defined as a separate categorical covariate (occurrence of 0,1 , or 2 times of the minor allele for SNPs and the occurrence of 0, 1, or 2 times of the haplotype). SNPs being components of a haplotype were only regarded within the respective haplotypes and were not additionally tested as separate predictors.

Second, the additional contribution of the genetic predictors to the prediction of the selected psychological predictors was assessed. Therefore, separate Cox regression analyses were again conducted for pain intensity and pain disability including the respective psychological variable in a first block of the Cox regression (the attentional bias toward positive words for predicting pain intensity and the pain vigilance for predicting pain disability) and adding all genetic variables in a second block. The statistical method for selecting predictor variables in these additional analyses was again stepwise forward procedure to identify the best possible pattern of prediction.

Statistical analyses were run using the SPSS software, Version 19 for Windows (IBM Corporation, Armonk, NY, USA). Statistical significance was set at $\alpha=0.05$ for all analyses.

\section{Effect sizes estimation}

Additionally, to reveal the strength of differences between the low and high pain intensity and disability groups as regards the predictors at the end point of survival time 1 year after surgery, effect sizes (Cohen's $d$ ) were calculated. For comparing the effect sizes of the genetic and psychological predictors, we computed the common effect size measure Cohen's $d^{45}$ for both predictor groups via a computer-based tool for meta-analysis (Comprehensive Meta-Analysis software version 2.0 for Windows, Biostat, Inc., Englewood, NJ, USA). With respect to the genetic predictors, first genotypes and haplotypes were assigned to pain and disability groups according to the presence of the minor allele (recessive hereditary model). Group frequencies were then estimated by $2 \times 2$ cross tabulations conducted between carriers and noncarriers of the minor allele and the outcome groups. The estimated frequency statistics were then used for the calculation of effect sizes regarding the genetic predictors. 


\section{Results}

\section{Descriptive statistics of clinical data and the final set of genetic predictors}

Descriptive statistics of the psychological predictors and postoperative outcome of the sample are shown in Table 2.

The attentional bias score for positive words had a negative value suggesting lower attentional preference of the patients for positive words. Low pain intensity and disability were reached by $83(92.2 \%)$ of the patients at 1 year after surgery, however, not necessarily by the same patients (Table 2 ). Survival curves for the proportion of patients reporting high pain intensity and disability during the postoperative time course are shown in Figure 1. The highest rating scores in both measures of postoperative pain (mean $[\mathrm{SD}]=3.88[2.00]$ for pain intensity; mean [SD] $=36.67$ [15.79] for pain disability) were reached at 1 week postsurgery and declined in time reaching the lowest values at 1 year after surgery (mean $[\mathrm{SD}]=0.69$ [1.02] for pain intensity; mean $[\mathrm{SD}]=2.00$ [3.63] for pain disability) (Table 2). Taking into account that pain intensity and disability scores were not normally distributed, Friedman's tests were conducted for detecting differences in the scores of pain intensity and pain disability over the four postoperative points. The results revealed significant effects of time on pain intensity $\left(\chi^{2}(3,0)=145.027, P<0.001\right)$ and pain disability $\left(\chi^{2}(3,0)=198.991, P<0.001\right)$. Post hoc analyses using the Wilcoxon test showed significant decreases in the scores of pain intensity and disability over all postoperative points in time (for pain intensity: $Z_{\mathrm{T} 1-\mathrm{T} 2 / \mathrm{T2}-\mathrm{T} 3 \mathrm{T3}-\mathrm{T} 4}=[(-3.050)-$ $(-6.805)], P \leq 0.002$; for pain disability: $Z_{\mathrm{T} 1-\mathrm{T} 2 / \mathrm{T2}-\mathrm{T} 3 / \mathrm{T3}-\mathrm{T} 4}=$ $[(-3.491)-(-7.406)], P<0.001)$.
The distribution of the homozygous and heterozygous carriers of all SNPs agree with the expectations of the HardyWeinberg law $\left(\chi^{2}\right.$ goodness-of-fit test, $P=[0.169-1.00]$. Two haploblocks were estimated between SNPs located in the COMT gene, spanning rs4646312, rs165722, rs6269, rs4633, rs4818, and rs4680 (linkage disequilibrium [LD] 97\%), and in the NK1R gene, spanning rs6741029 and rs 735668 (LD 93\%). Subsequently, six haplotypes were computed for the COMT and four for the NK1R gene (Table 1). Two of the COMT haplotypes and three of the NK1R haplotypes fulfilled the criterion of MAF $>10 \%$ and were submitted to analysis. The first COMT haplotype rs $4646312 \mathrm{C} / \mathrm{rs} 165722 \mathrm{C} /$ rs $6269 \mathrm{G} / \mathrm{rs} 4633 \mathrm{C} / \mathrm{rs} 4818 \mathrm{G} / \mathrm{rs} 4680 \mathrm{G}$ was composed of the minor alleles and the second one, COMT rs4646312T/ rs $165722 \mathrm{~T} / \mathrm{rs} 6269 \mathrm{~A} / \mathrm{rs} 4633 \mathrm{~T} / \mathrm{rs} 4818 \mathrm{C} / \mathrm{rs} 4680 \mathrm{~A}$, consisted of the major alleles. The three NK1R haplotypes, NK1R rs6741029T/rs735668A, NK1R rs6741029G/rs735668C, and $N K 1 R$ rs6741029G/rs735668A, were composed of the minor alleles, the major alleles, and a combination, respectively. All the remaining eight SNPs had a MAF $>10 \%$ and were submitted to statistical analysis. Finally, the resulting set of genetic predictors comprised eight SNPs and five haplotypes (Table 1, relevant SNPs and haplotypes marked in bold).

\section{Prediction of postoperative outcome by the genetic variables}

The postoperative time course of pain intensity and disability was first tested for influences of the genetic factors. Stepwise Cox regression analyses identified no significant effects of any of the genetic predictors on survival time up

Table 2 Clinical characteristics of the sample

\begin{tabular}{|c|c|c|c|c|c|}
\hline \multirow[t]{2}{*}{ Parameter } & \multirow{2}{*}{$\begin{array}{l}\text { Preoperative } \\
\text { assessment } \\
\text { I day presurgery }\end{array}$} & \multicolumn{4}{|c|}{$\begin{array}{l}\text { Postoperative } \\
\text { assessment }\end{array}$} \\
\hline & & I week & 3 months & 6 months & I year \\
\hline Psychological variables & Mean (SD) & & & & \\
\hline Attentional bias score for positive words & $-5.88(46.57)$ & & & & \\
\hline PVAQ score & $33.33(12.21)$ & & & & \\
\hline Postoperative pain characteristics & Mean (SD) & & & & \\
\hline Pain intensity ratings & & $3.88(2.00)$ & $1.64(1.57)$ & 1.19 ( 1.49$)$ & $0.69(1.02)$ \\
\hline Pain disability index & & 36.67 (I5.79) & $12.81(12.37)$ & $4.23(7.34)$ & $2.00(3.63)$ \\
\hline Classification in low/high levels of postoperative pain ${ }^{a}$ & $N(\%)$ & & & & \\
\hline \multicolumn{6}{|l|}{ Pain intensity ratings } \\
\hline Low pain intensity & & $25(27.80)$ & $69(76.70)$ & $78(86.70)$ & $83(92.20)$ \\
\hline High pain intensity & & $65(72.20)$ & $21(23.30)$ & $12(13.30)$ & $7(7.80)$ \\
\hline \multicolumn{6}{|l|}{ Pain disability index } \\
\hline Low pain disability & & $5(5.60)$ & $42(46.70)$ & $78(86.70)$ & $83(92.20)$ \\
\hline High pain disability & & $85(94.40)$ & $48(53.30)$ & $12(13.30)$ & $7(7.80)$ \\
\hline
\end{tabular}

Notes: ${ }^{a}$ According to the pain intensity ratings $([0-2]=$ low pain intensity, $[3-10]=$ high pain intensity) and the pain disability score $([0-8]=$ low pain disability, $[9-70]=$ high pain disability at the respective assessment points in time).

Abbreviations: SD, standard deviation; PVAQ, Pain Vigilance and Awareness Questionnaire. 


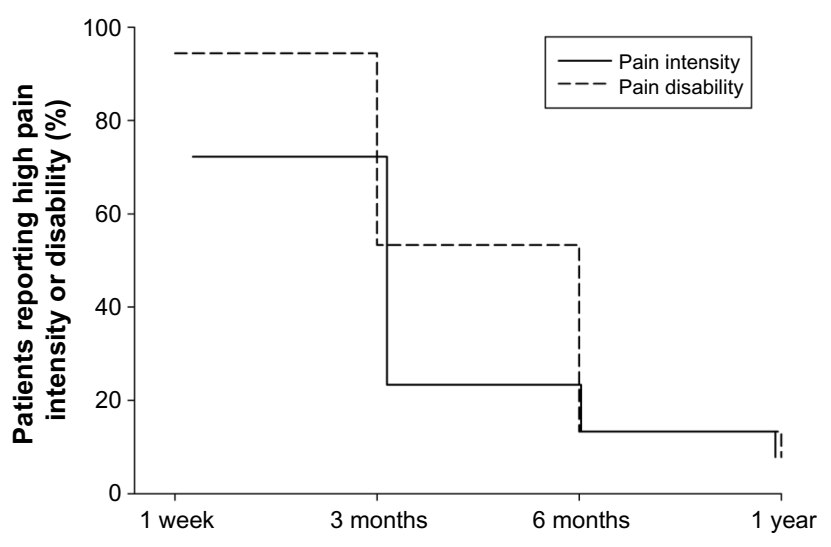

Figure I Survival curves of the percentage of patients reporting high pain intensity and disability during the postoperative time course up to I year after surgery.

to 1 year after surgery. Table 3 displays the score statistics $\left(\chi^{2}\right.$ value, $\mathrm{df}, P$ ) for the genetic predictors that could not surpass the threshold $\alpha$-level of 0.05 . The $\chi^{2}$ values are given for each SNP and haplotype as a categorical covariate where the occurrence of the minor allele for the $\operatorname{SNPs}(0,1$, or 2 times) and the occurrence of the haplotype $(0,1$, or 2 times) are defined.

\section{Prediction of postoperative outcome by the psychological and genetic variables}

Given the lack of a statistical evidence for an influence of the genetic predictors on pain-associated postoperative outcome, the relative contribution of the genetic predictors to the predictions of pain intensity by the attentional bias for positive words and of pain disability by the PVAQ was tested. However, none of the genetic predictors could improve the goodness of prediction by each of the psychological predictors. The initial score statistics of the genetic variables entered all together as a second block of the respective regression analysis had the same values as displayed in Table 3 because of the same stepwise forward method used for statistical selection of the best possible predictors. In summary, the values ranged again between $\chi^{2}=[0.000-2.265], P>0.332$ for pain intensity and between $\chi^{2}=[0.001-3.785], P>0.151$ for disability. The Cox regression analysis for predicting the survival time of pain disability showed that the PVAQ score was a significant predictor and was the only covariate entered in the final model. The residual chi-square statistics for the genetic variables showed scores ranging between $\chi^{2}=[0.003-5.161]$ that were again not significant at $\alpha=0.05$. High preoperative PVAQ scores were significantly associated with low likelihood to reach low pain-related disability fast $\left(\chi^{2}[\mathrm{df}=1]=4.512, \mathrm{HR}=0.980,95 \%\right.$ confidence interval
$0.962-0.998, P=0.034)$. For example, patients in the upper quartile of the PVAQ mean sum score $(\geq 40.25)$ required a mean time of 24.55 weeks until recovery, whereas patients with a PVAQ score in the lower quartile $(\leq 27.00)$ took on average only 16.40 weeks. However, the value of the HR reaching almost 1 suggested that this effect was at best small. In contrast, the attentional bias for positive words could not significantly predict the survival time until the patients reached low pain intensity $\left(\chi^{2}[\mathrm{df}=1]=0.481, P=0.488\right)$.

\section{Effect sizes}

Subsequently, effect sizes (Cohen's $d$ ) were calculated according to the outcome in pain intensity and disability at the assessment point 1 year after surgery (Table 4 ). For example, for the COMT haplotype composed of the minor alleles of the polymorphisms rs $4646312 \mathrm{~T}>\mathrm{C} / \mathrm{rs} 165722 \mathrm{~T}>\mathrm{C} /$ $\mathrm{rs} 6269 \mathrm{~A}>\mathrm{G} / \mathrm{rs} 4633 \mathrm{~T}>\mathrm{C} / \mathrm{rs} 4818 \mathrm{C}>\mathrm{G} / \mathrm{rs} 4680 \mathrm{~A}>\mathrm{G}$, the effect sizes reached almost medium values regarding both pain intensity and disability; the polymorphism IL $1 \mathrm{~A}$ rs $1800587 \mathrm{G}>\mathrm{A}$ had also similar effect size for pain disability. For some polymorphisms, the effect size calculation was based on frequencies of cases per cell that were lower than the minimum number required for a valid interpretation ( $n<2$ expected and $n<1$ observed frequencies). For these genetic predictors, the effect sizes were considered only as preliminary and were not further interpreted (Table 4, $d$ values marked in gray). Comparable to the effects of the genetic variables on pain intensity, the attentional bias for positive words reached only a small effect size (Table 4). In contrast, the PVAQ score surpassed the border for large effects $(d=0.822)$.

\section{Summary of results}

Cox regression analyses testing for influences of the genetic predictors on the course of postoperative pain intensity and disability could not reveal significant results. This was also the case when genetics were entered as additional variables to the prediction of postoperative outcome by the psychological predictors found to be effective in an earlier analysis in this sample. Effect size estimation revealed small to medium effects on pain intensity and disability at assessment time point 1 year after surgery for some genetic predictors. The PVAQ was associated with persistent pain disability on slightly significant level. The effect size reached a value for large effects suggesting higher levels of preoperatively reported pain vigilance as risk factor for long-term pain disability. 
Table 3 The prediction of survival time by the genetic predictors (genotypes and haplotypes), for pain intensity and pain disability, respectively

\begin{tabular}{|c|c|c|c|c|c|c|c|c|c|c|}
\hline \multirow{2}{*}{$\begin{array}{l}\text { Genetic predictors } \\
\text { (genotypes and haplotypes) }\end{array}$} & \multicolumn{5}{|c|}{ Pain intensity } & \multicolumn{5}{|c|}{ Pain disability } \\
\hline & $\chi^{2}$ & $d f$ & $P$-value & $\mathbf{H R}^{\mathbf{c}}$ & $\mathrm{Cl}$ & $\chi^{2}$ & $d f$ & $P$-value & $\mathbf{H R}^{\mathrm{c}}$ & $\mathrm{Cl}$ \\
\hline \multicolumn{11}{|l|}{ ILIA rsI800587 G>A } \\
\hline $\mathrm{AA}^{\mathrm{a}}$ & 0.773 & 2 & 0.680 & - & - & 0.267 & 2 & 0.875 & - & - \\
\hline AG & 0.753 & I & 0.386 & - & - & 0.192 & I & 0.661 & - & - \\
\hline GG & 0.346 & I & 0.556 & - & - & 0.024 & I & 0.877 & - & - \\
\hline \multicolumn{11}{|l|}{ FAAH rs4I4I964 C >T } \\
\hline $\mathrm{TT}^{\mathrm{a}}$ & 0.679 & 2 & 0.712 & - & - & 0.863 & 2 & 0.650 & - & - \\
\hline $\mathrm{CT}$ & 0.148 & I & 0.700 & - & - & 0.145 & I & 0.703 & - & - \\
\hline $\mathrm{CC}$ & 0.088 & I & 0.767 & - & - & $0.77 \mathrm{I}$ & I & 0.380 & - & - \\
\hline \multicolumn{11}{|l|}{ FAAH rs2295633 G $>$ A } \\
\hline $\mathrm{AA}^{\mathrm{a}}$ & 0.277 & 2 & $0.87 \mid$ & - & - & 1.634 & 2 & 0.442 & - & - \\
\hline AG & 0.193 & I & 0.660 & - & - & 0.172 & I & 0.679 & - & - \\
\hline GG & 0.010 & I & 0.920 & - & - & 1.326 & I & 0.249 & - & - \\
\hline \multicolumn{11}{|l|}{ NKIR rs67I5729 G>A } \\
\hline $\mathrm{AA}^{\mathrm{a}}$ & 0.900 & 2 & 0.638 & - & - & 0.182 & 2 & 0.913 & - & - \\
\hline AG & 0.000 & I & 0.984 & - & - & 0.046 & I & 0.831 & - & - \\
\hline GG & 0.514 & I & 0.473 & - & - & 0.180 & $\mathrm{I}$ & 0.672 & - & - \\
\hline \multicolumn{11}{|l|}{ NR3C2 rs207095 I C $>\mathbf{G}$} \\
\hline $\mathrm{GG}^{\mathrm{a}}$ & 0.004 & 2 & 0.998 & - & - & 0.878 & 2 & 0.645 & - & - \\
\hline CG & 0.000 & I & 0.989 & - & - & 0.877 & $\mathrm{I}$ & 0.349 & - & - \\
\hline $\mathrm{CC}$ & 0.004 & I & 0.953 & - & - & 0.288 & I & 0.592 & - & - \\
\hline \multicolumn{11}{|l|}{ OPRDI rs22349 I $8 \mathrm{~T}>\mathrm{C}$} \\
\hline $\mathrm{CC}^{\mathrm{a}}$ & 0.241 & 2 & 0.887 & - & - & 3.785 & 2 & 0.151 & - & - \\
\hline $\mathrm{CT}$ & 0.023 & I & 0.879 & - & - & 0.914 & I & 0.339 & - & - \\
\hline TT & 0.024 & I & 0.876 & - & - & 0.004 & I & 0.948 & - & - \\
\hline \multicolumn{11}{|l|}{ TGFBI rsI800469 G>A } \\
\hline $\mathrm{AA}^{\mathrm{a}}$ & 0.503 & 2 & 0.777 & - & - & 0.287 & 2 & 0.867 & - & - \\
\hline AG & 0.315 & I & 0.575 & - & - & 0.265 & I & 0.607 & - & - \\
\hline GG & 0.497 & I & 0.481 & - & - & 0.228 & I & 0.633 & - & - \\
\hline \multicolumn{11}{|l|}{ TRPVI rs8065080 T $>C$} \\
\hline $\mathrm{CC}^{\mathrm{a}}$ & 2.265 & 2 & 0.322 & - & - & 2.379 & 2 & 0.304 & - & - \\
\hline CT & 0.002 & I & 0.965 & - & - & 2.367 & I & 0.124 & - & - \\
\hline TT & 0.868 & I & 0.352 & - & - & 1.265 & I & 0.261 & - & - \\
\hline \multicolumn{11}{|l|}{ СОМТ C/C/G/C/G/G } \\
\hline $2 x^{b}$ & 0.757 & 2 & 0.685 & - & - & 0.846 & 2 & 0.655 & - & - \\
\hline $\mathrm{IX}$ & 0.151 & I & 0.697 & - & - & 0.823 & I & 0.364 & - & - \\
\hline No & 0.049 & I & 0.826 & - & - & 0.638 & I & 0.424 & - & - \\
\hline \multicolumn{11}{|l|}{ СОМT T/T/A/T/C/A } \\
\hline $2 x^{b}$ & 0.968 & 2 & 0.616 & - & - & 0.234 & 2 & 0.889 & - & - \\
\hline IX & 0.155 & I & 0.694 & - & - & 0.180 & 1 & 0.671 & - & - \\
\hline No & 0.325 & I & 0.569 & - & - & 0.168 & I & 0.682 & - & - \\
\hline \multicolumn{11}{|l|}{ NKIR T/Af } \\
\hline $2 x^{b}$ & 0.047 & 2 & 0.997 & - & - & 0.328 & 2 & 0.849 & - & - \\
\hline IX & 0.039 & I & 0.843 & - & - & 0.001 & I & 0.980 & - & - \\
\hline No & 0.045 & I & 0.832 & - & - & 0.147 & I & 0.701 & - & - \\
\hline \multicolumn{11}{|l|}{$N K I R$ G/Ag } \\
\hline $1 x^{b}$ & - & - & - & - & - & - & - & - & - & - \\
\hline No & 0.010 & I & 0.922 & - & - & 0.001 & I & 0.980 & - & - \\
\hline \multicolumn{11}{|l|}{$N K I R G / C^{h}$} \\
\hline $2 x^{b}$ & 0.108 & 2 & 0.948 & - & - & 1.392 & 2 & 0.499 & - & - \\
\hline IX & 0.044 & I & 0.833 & - & - & 1.254 & I & 0.263 & - & - \\
\hline No & 0.107 & I & 0.744 & - & - & 0.882 & I & 0.348 & - & - \\
\hline
\end{tabular}

Notes: Genetic predictors are displayed as genotypes or haplotypes in alphabetical order, ${ }^{a}$ reference category in the Cox regression analysis comprising the homozygous carriage of the minor allele; breference category in the Cox regression analysis for comparing the occurrence of the haplotype (0, I, or 2 times present), $2 \times=$ haplotype present two times, $\mathrm{I} \times$ = haplotype present one time, no = haplotype not present; 'Hazard ratios are given in the statistical output of the Cox regression analysis only for variables included in the model surpassing the $\alpha$-level threshold of 0.05; ${ }^{\circ} \mathrm{COMT}$ rs46463I2C/rs I65722C/rs6269G/rs4633C/rs48I8G/rs4680G haplotype; ${ }^{\circ} \mathrm{COMT} \mathrm{rs} 46463$ I2T/rs I65722T/rs6269A/rs4633T/

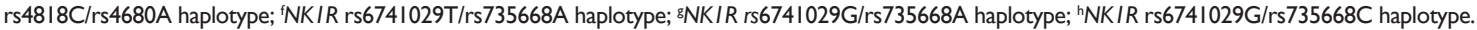

Abbreviations: df, degrees of freedom; HR, hazard ratio; Cl, confidence interval; COMT, cathechol-O-methyl transferase gene; $F A A H$, fatty acid amino hydrolase gene; IL IA, interleukin I alpha gene; NKIR, tachykinin receptor I gene; NR3C2, nuclear receptor, subfamily 3, group C, member 2 gene; OPRD I, $\delta$-opioid receptor gene; TGFB I, transforming growth factor, beta I gene; TRPVI, transient receptor potential cation channel, subfamily V, member I gene. 
Table 4 Effect size measures for predictor variables at the latest postoperative session I year after surgery

\begin{tabular}{|c|c|c|}
\hline \multirow{2}{*}{$\begin{array}{l}\text { Predictor of I-year } \\
\text { postoperative outcome }\end{array}$} & Pain intensity & Pain disability \\
\hline & \multicolumn{2}{|l|}{ Cohen's d } \\
\hline \multicolumn{3}{|c|}{ Genetic predictors (SNPs and haplotypes) } \\
\hline ILIA rsI800587 G>A & 0.975 & 0.465 \\
\hline FAAH rs4I4I964 C>T & 0.191 & -0.184 \\
\hline FAAH rs2295633 G>A & 0.220 & -0.155 \\
\hline$N K I R$ rs67I5729 G>A & 0.041 & 0.555 \\
\hline$N R 3 C 2$ rs207095। $C>G$ & -0.474 & 0.972 \\
\hline OPRD / rs22349|8 T>C & -0.244 & -0.244 \\
\hline TGFB I rsI800469 G >A & -0.333 & -1.217 \\
\hline TRPVI rs8065080 T>C & -0.070 & 0.304 \\
\hline COMT C/C/G/C/G/Ga & 0.304 & -0.416 \\
\hline COMT T/T/A/T/C/A & -0.374 & -0.374 \\
\hline$N K I R T / A^{c}$ & -0.416 & -0.070 \\
\hline$N K I R G / A^{d}$ & 0.280 & 0.164 \\
\hline$N K I R \mathrm{G} / \mathrm{C}^{\mathrm{e}}$ & $0.04 I$ & -0.243 \\
\hline \multicolumn{3}{|l|}{ Psychological predictors } \\
\hline Attentional bias for positive words & 0.004 & \\
\hline PVAQ & & 0.822 \\
\hline
\end{tabular}

Notes: Effect sizes given in gray correspond to $2 \times 2$ cross tabulations where either expected or observed frequencies were lower $n<2$ and cannot be considered as valid results. The algebraic sign denotes the direction of effects regarding the difference between carriers of the minor allele and noncarriers of the same. ${ }^{a} \mathrm{COMT}$ haplotype rs46463I2C/rs165722C/rs6269G/rs4633C/rs48I8G/rs4680G; ' ${ }^{\circ} C O M T$ haplotype rs46463I2T/rsI65722T/rs6269A/rs4633T/rs48I8C/rs4680A; cNKIR rs674I029T/ rs735668A; ${ }^{d} N K I R$ rs674I029G/rs735668A; ${ }^{e} N K I R$ rs6741029G/rs735668C; $d \geq 0.3$, $d \geq 0.5$, and $d \geq 0.8$ for small, medium, and large effects, respectively.

Abbreviations: SNP, single nucleotide polymorphism; PVAQ, Pain Vigilance and Awareness Questionnaire; COMT, cathechol-O-methyl transferase gene; $F A A H$, fatty acid amino hydrolase gene; ILIA, interleukin I alpha gene; NKIR, tachykinin receptor I gene; NR3C2, nuclear receptor, subfamily 3, group C, member 2 gene; OPRDI, $\delta$-opioid receptor gene; TGFBI, transforming growth factor, beta I gene; TRPVI, transient receptor potential cation channel, subfamily $\mathrm{V}$, member I gene.

\section{Discussion}

In the present study, we investigated whether SNPs in candidate pain genes were associated with pain-related outcome up to 1 year after surgery in a sample of preoperatively pain-free male patients undergoing funnel chest correction. Because the patients had not have any severe pain prior to surgery, the present surgical model provided ideal conditions for studying the development of chronic postoperative pain. SNPs were chosen to be located in genes involved in inflammation and immune response, as well as in genes frequently investigated in pain genetic research. ${ }^{9}$ The genetic predictors could not significantly contribute to the explanation of the time course of postoperative pain intensity and pain-related disability up to 1 year after surgery. Also, no statistically meaningful effects could be found when the genetic variables were tested as additional predictors adding explained variance to two psychological variables that proved to have high explanatory power for persistent postoperative pain intensity and disability in a previous study. ${ }^{15}$ Effect size estimation suggested low impact of the genetic predictors on both pain intensity and disability. Concerning the psychological predictors, the preoperative PVAQ score proved again to be a relevant predictor for lasting pain disability after surgery. In contrast, the preoperatively measured attentional bias to positive words assessed in a dot-probe task failed this time to predict chronic pain intensity.

The genetic variants previously reported to modulate pain in humans were not found to have meaningful influence on the course of pain-related outcome in the present clinical setting. The variants in the selected genes appeared not to be crucially involved in long-term consequences of thoracic tissue damage due to surgery. In fact, we tested genetic effects on the transition from acute to persistent postoperative pain and long-standing functional disability. Indeed, there is to date no evidence for genetic associations with the development of postoperative chronic pain ${ }^{46}$ after surgically produced tissue damage in preoperatively pain-free individuals. In contrast to the present cohort, populations investigated in other genetic association studies on postoperative pain often already had pain as a symptom of disease prior to surgery. ${ }^{13,47}$ However, even for SNPs or haplotypes in candidate genes frequently assessed in pain genetics, such as COMT, FAAH, or IL1A, ${ }^{9}$ no significant effects on pain continuation after surgery and its consequences could be found. Among these, variants in $C O M T^{13,47}$ and $\mathrm{GCH}^{48}$ genes had also been reported to affect the chronification of pain after surgery.

To further elucidate possible genetic effects that might not have been strong enough to surpass the level of significance, we additionally quantified the effects of the genetic predictors on postoperative outcome 1 year after surgery using effect sizes. Again, most of the genetic predictors had no meaningful impact. Nevertheless, some of them could reach small to medium effect sizes. The COMT haplotype composed of the minor alleles rs4646312T $>\mathrm{C} / \mathrm{rs} 165722 \mathrm{~T}>\mathrm{C} / \mathrm{rs} 6269 \mathrm{~A}>\mathrm{G} /$ rs $4633 \mathrm{~T}>\mathrm{C} / \mathrm{rs} 4818 \mathrm{C}>\mathrm{G} / \mathrm{rs} 4680 \mathrm{~A}>\mathrm{G}$ could be identified to have up to medium effect sizes on both pain intensity and disability at 1 year after surgery. The polymorphism IL1A rs $1800587 \mathrm{G}>\mathrm{A}$ reached similar effects on 1-year disability outcome. The $I L 1 A$ gene codes for a proinflammatory protein of the cytokine family usually released as inflammatory or immune response. In our study, carriers of the minor allele of the $I L 1 A$ polymorphism seem to be at higher risk for longstanding disability. The COMT gene codes for an enzyme acting in the metabolism of catecholamines, such as dopamine and epinephrine. The COMT haplotype composed of the minor alleles was associated with persistent pain intensity but less disability at 1 year after surgery. Notably, such interpre- 
tations give a hint for further investigation rather than being definitive results as they are based on nonsignificant results in the main analyses and post hoc interpretations of the effect size calculations. However, for both genes, previous evidence exists showing association between variants in these genes and chronic pain. Specifically, simultaneous carriage of ILIA rs $1800587 \mathrm{C}>\mathrm{T}$ and $I L 1 R N$ rs $2234677 \mathrm{G}>\mathrm{A}$ was a risk factor for low back pain and was also associated with reported pain intensity. ${ }^{49}$ The homozygous $\mathrm{TT}^{889}(\mathrm{rs} 1800587 \mathrm{C}>\mathrm{T})$ genotype was shown to enhance the transcriptional activity of the $I L 1 A$ gene..$^{50}$ Translated to our results, this could mean that carriers of the minor allele have an increased production of messenger RNA and thus protein leading to a stronger proinflammatory regulation. The COMT haplotype ATCA (rs6269, rs4633, rs4818, rs4680) was associated with less pain disability and greater relief after lumbar disk surgery. ${ }^{47}$ Diatchenko et al reported, however, an opposite relationship between the same haplotype and experimental pain sensitivity. ${ }^{51}$

Furthermore, the effect sizes obtained for our genetic predictors of postoperative pain development were comparable to the effect sizes reported recently for several frequently occurring variants in human genes shown to modulate pain. ${ }^{52}$ Doehring et $\mathrm{al}^{52}$ estimated effect sizes for the impact of SNPs in the OPRM1, OPRD1, COMT, FAAH, GCH1, TRPV1 genes, and transient receptor potential cation channel, subfamily A, member 1 gene (TRPA1) on experimental pain thresholds to different stimuli. The genetic variants reached mainly modest, in some cases medium to high effect sizes (Cohen's $d=0.0-1.8$ ). The COMT rs4646312C/rs165722C/ rs6269G/rs4633C/rs4818G/rs4680G haplotype reached up to medium effect sizes in our study. Doehring et al also reported only small effect sizes on pain thresholds for cold and heat, electrical and blunt pressure stimuli $(d=0.06-0.23$, recessive hereditary model) for the same haplotype as assessed in our study.

Notably, it has been discussed that the reproducibility of genetic effects in pain research is often only modest $t^{6}$ and may not be verified by meta-analysis. Moreover, reproducibility of effects may be reduced by the coexistence of frequent variants in a single individual that act as confounders canceling out effects on phenotype..$^{53}$ However, even for these two seemingly major influential genetic variables $I L 1 A$ and COMT, the effects were below the effect shown for the preoperatively assessed pain hypervigilance as assessed by the questionnaire PVAQ. The self-reported attentional engagement toward pain-related bodily sensations had a large effect $(d=0.82)$. Similarly,
Doehring et $\mathrm{al}^{52}$ reported that the SNPs they assessed had smaller effect sizes compared with those of gender and sensitization by capsaicin. It seems important to consider such results when comparing genetic influences with those of other relevant factors.

Furthermore, our findings on the psychological predictors additionally indicate that it is of high clinical relevance to compare between pathophysiologically different predictor groups. We have already reported on the strength of the two psychological variables used in the present study to explain persistent pain and disability at 3 months and 6 months after surgery. ${ }^{15}$ Here, in this second analysis in the same but enlarged sample of patients, the PVAQ was the only significant predictor of survival time, even though the corresponding HR suggested low explanatory power. Individuals with higher levels of preoperatively reported pain vigilance tended to be at a risk for still experiencing pain-related disability at 1 year after surgery. The PVAQ also reached the highest effect size among all predictors, again supporting our previous results. In contrast, the attentional bias for positive words, assessed by the dot-probe task, was not able to explain lasting pain in the present study, thus complementing our previous results concerning persistent pain at 3 months and 6 months postsurgery. ${ }^{15}$ While at earlier time points, both psychological factors appeared to play a major role in the chronification process (Cohen's $d=0.5-0.7$ ), the PVAQ remains the only psychological predictor when considering the final outcome 1 year postsurgery.

Pain research increasingly recognizes the necessity of addressing the complexity of pain phenotypes by considering large sets of risk and resilience factors as well as their interaction in explanatory models. In this sense, the present analysis has made use of two major predictor groups based on genetic and psychological risk factors in a comparative approach for explaining persistent pain after cosmetic thoracic surgery. Although no significant additive effects of the genetic with the psychological predictors could be shown, the results adumbrate concomitant influences of both predictor groups on chronic postoperative pain. Advanced analysis of the combined effects of genetic and psychological factors on long-standing consequences after surgery, for example, via classification and regression tree algorithms, are to be recommended for future studies on larger samples. Such combined examinations have already been reported for $O P R D 1$ and $T R P V 1$ variants on experimental pain sensitivity in dependence of personality traits, ${ }^{54}$ and COMT polymorphisms in interaction with pain-related catastrophic thinking and depressive mood on shoulder pain..$^{55,56}$ 
There are some limitations of the present study. It is important to note that the study might be underpowered because of the small sample size. This is a clear limitation, probably leading to an underestimation of a genetic effect. Due to this limitation, certain allele groups were very small, and for some of the genetic variables, the results on the effect sizes could not be validly interpreted. Furthermore, the study sample comprised only young male patients undergoing funnel chest correction. This should be kept in mind when the results are transferred to other types of postoperative pain. Next, the present assessment has started a while ago with 31 pain-related genetic polymorphisms that built a comprehensive set of possible relevant genetic modulators at this time. However, it meanwhile represents a small subset from $>400$ genes being currently proven for their involvement in the multifactorial pathophysiology of pain. ${ }^{29}$ Finally, we tested possible multigene effects on the development of persistent postoperative pain in terms of statistically added explained variance by entering single genetic predictors but not their interaction in the regression model. This approach cannot fully consider functional interaction effects of genes on phenotype such as the coexistence of variants with opposite functional consequences on pain in the same individual; 53 for example, $F A A H$ rs $2295633 \mathrm{G}>\mathrm{A}^{57}$ and TRPV1 $\mathrm{rs} 8065080 \mathrm{~T}>\mathrm{C}^{54}$ have been shown to be associated with increased and reduced pain sensitivity, respectively.

\section{Conclusion}

In conclusion, our results showed that common genetic variants previously associated with or functionally related to pain perception could not significantly predict the development of chronic postoperative pain as assessed in a longitudinal design in initially pain-free patients undergoing cosmetic thoracic surgery. According to effect size estimation, some promising suggestions for relevant genetic modulators could be made, as for a genetic variant of the ILIA gene and a haplotype of commonly investigated variants in the COMT gene. A comparison between pathophysiologically different predictor groups might help to identify clinically relevant predictors for chronic pain.

\section{Acknowledgments}

This study was supported by the Deutsche Forschungsgemeinschaft (La 685/6, SL). The research also received funding, in particular additional personnel costs, from the Else Kröner Fresenius Foundation (EKFS), Research Training Group Translational Research Innovation - Pharma (TRIP, JL). The funders had no role in method design, data selection, and analysis, decision to publish, or preparation of the manuscript.

\section{Disclosure}

The authors report no conflicts of interest in this work.

\section{References}

1. Kehlet H, Jensen TS, Woolf CJ. Persistent postsurgical pain: risk factors and prevention. Lancet. 2006;367(9522):1618-1625.

2. Deumens R, Steyaert A, Forget P, et al. Prevention of chronic postoperative pain: cellular, molecular, and clinical insights for mechanism-based treatment approaches. Prog Neurobiol. 2013;104:1-37.

3. Mogil JS, Grisel JE. Transgenic studies of pain. Pain. 1998;77(2): 107-128.

4. Lacroix-Fralish ML, Mogil JS. Progress in genetic studies of pain and analgesia. Annu Rev Pharmacol Toxicol. 2009;49:97-121.

5. Lötsch J, Geisslinger G. Current evidence for a modulation of nociception by human genetic polymorphisms. Pain. 2007;132(1-2): $18-22$.

6. Lötsch J, Geisslinger G. A critical appraisal of human genotyping for pain therapy. Trends Pharmacol Sci. 2010;31(7):312-317.

7. Mogil JS. Are we getting anywhere in human pain genetics? Pain. 2009;146(3):231-232.

8. Lacroix-Fralish ML, Ledoux JB, Mogil JS. The Pain Genes Database: an interactive web browser of pain-related transgenic knockout studies. Pain. 2007;131(1-2):3. e1-e4.

9. Mogil JS. Pain genetics: past, present and future. Trends Genet. 2012;28(6):258-266.

10. Stephens K, Cooper BA, West C, et al. Associations between cytokine gene variations and severe persistent breast pain in women following breast cancer surgery. J Pain. 2014;15(2):169-180.

11. Henker RA, Lewis A, Dai F, et al. The associations between OPRM 1 and COMT genotypes and postoperative pain, opioid use, and opioidinduced sedation. Biol Res Nurs. 2013;15(3):309-317.

12. Kambur O, Kaunisto MA, Tikkanen E, Leal SM, Ripatti S, Kalso EA. Effect of catechol-O-methyltransferase-gene (COMT) variants on experimental and acute postoperative pain in 1,000 women undergoing surgery for breast cancer. Anesthesiology. 2013;119(6): 1422-1433.

13. Lee PJ, Delaney P, Keogh J, Sleeman D, Shorten GD. CatecholamineO-methyltransferase polymorphisms are associated with postoperative pain intensity. Clin J Pain. 2011;27(2):93-101.

14. Kolesnikov Y, Gabovits B, Levin A, et al. Chronic pain after lower abdominal surgery: do catechol-O-methyl transferase/opioid receptor mu-1 polymorphisms contribute? Mol Pain. 2013;9:19.

15. Lautenbacher S, Huber C, Schöfer D, et al. Attentional and emotional mechanisms related to pain as predictors of chronic postoperative pain: a comparison with other psychological and physiological predictors. Pain. 2010;151(3):722-731.

16. Margraf J. Diagnostisches Kurz-Interview bei psychischen Störungen. Berlin: Springer; 1994.

17. Weber PG, Hummer HP. Die "neue" Erlanger Trichterbrustkorrektur Minimalisierung eines bewährten Verfahrens [The "new" Erlangen technique of funnel chest correction - minimalization of a well working procedure]. Zentralbl Chir. 2006;131(6):493-498.

18. McCracken LM. "Attention" to pain in persons with chronic pain: a behavioural approach. Behav Res Ther. 1997;28:271-284.

19. Lautenbacher S, Huber C, Kunz M, et al. Hypervigilance as predictor of postoperative acute pain: its predictive potency compared with experimental pain sensitivity, cortisol reactivity, and affective state. Clin J Pain. 2009;25(2):92-100.

20. Seneviratne C, Ait-Daoud N, Ma JZ, Chen G, Johnson BA, Li MD. Susceptibility locus in neurokinin-1 receptor gene associated with alcohol dependence. Neuropsychopharmacology. 2009;34(11):2442-2449. 
21. van Leeuwen N, Kumsta R, Entringer S, et al. Functional mineralocorticoid receptor $(\mathrm{MR})$ gene variation influences the cortisol awakening response after dexamethasone. Psychoneuroendocrinology. 2010;35(3):339-349.

22. Ashburner M, Ball CA, Blake JA, et al. Gene ontology: tool for the unification of biology. The Gene Ontology Consortium. Nat Genet. 2000;25(1):25-29.

23. Camon E, Magrane M, Barrell D, et al. The Gene Ontology Annotation (GOA) Database: sharing knowledge in Uniprot with Gene Ontology. Nucleic Acids Res. 2004;32(Database issue):D262-D266.

24. Thomas PD, Mi H, Lewis S. Ontology annotation: mapping genomic regions to biological function. Curr Opin Chem Biol. 2007;11(1):4-11.

25. Backes C, Keller A, Kuentzer J, et al. GeneTrail - advanced gene set enrichment analysis. Nucleic Acids Res. 2007;35(Web Server issue): W186-W192.

26. Keller A, Backes C, Al-Awadhi M, et al. GeneTrailExpress: a web-based pipeline for the statistical evaluation of microarray experiments. $B M C$ Bioinformatics. 2008;9:552.

27. Ultsch A, Lotsch J. What do all the (human) micro-RNAs do? BMC Genomics. 2014;15:976.

28. Ultsch A, Lotsch J. Functional abstraction as a method to discover knowledge in gene ontologies. PLoS One. 2014;9(2):e90191.

29. Lotsch J, Doehring A, Mogil JS, Arndt T, Geisslinger G, Ultsch A Functional genomics of pain in analgesic drug development and therapy. Pharmacol Ther. 2013;139(1):60-70.

30. Benjamini Y, Hochberg Y. Controlling the false discovery rate - a practical and powerful approach to multiple testing. $J$ R Stat Soc B. 1995;57:289-300.

31. Carbon S, Ireland A, Mungall CJ, et al; Web Presence Working Group. AmiGO: online access to ontology and annotation data. Bioinformatics. 2009;25(2):288-289.

32. Baum C, Huber C, Schneider R, Lautenbacher S. Prediction of experimental pain sensitivity by attention to pain-related stimuli in healthy individuals. Percept Mot Skills. 2011;112(3):926-946.

33. Dimova V, Horn C, Parthum A, et al. Does severe acute pain provoke lasting changes in attentional and emotional mechanisms of pain-related processing? A longitudinal study. Pain. 2013;154(12):2737-2744.

34. Keogh E, Ellery D, Hunt C, Hannent I. Selective attentional bias for pain-related stimuli amongst pain fearful individuals. Pain. 2001; 91(1-2):91-100

35. Lautenbacher S, Huber C, Baum C, Rossaint R, Hochrein S, Heesen M. Attentional avoidance of negative experiences as predictor of postoperative pain ratings and consumption of analgesics: comparison with other psychological predictors. Pain Med. 2011;12(4):645-653.

36. Nagel B, Gerbershagen HU, Lindena G, Pfingsten M. Entwicklung und empirische Überprüfung des Deutschen Schmerzfragebogens der DGSS [Development and evaluation of the multidimensional German pain questionnaire]. Schmerz. 2002;16(4):263-270.

37. Hardy GH. Mendelian proportions in a mixed population. Science. 1908;28:49-50.

38. Barrett JC, Fry B, Maller J, Daly MJ. Haploview: analysis and visualization of LD and haplotype maps. Bioinformatics. 2005;21(2):263-265.

39. Gabriel SB, Schaffner SF, Nguyen H, et al. The structure of haplotype blocks in the human genome. Science. 2002;296(5576):2225-2229.

40. Stephens M, Donnelly P. A comparison of bayesian methods for haplotype reconstruction from population genotype data. Am J Hum Genet. 2003;73(5):1162-1169.

41. Stephens M, Smith NJ, Donnelly P. A new statistical method for haplotype reconstruction from population data. Am J Hum Genet. 2001;68(4):978-989.

42. Farrar JT, Berlin JA, Strom BL. Clinically important changes in acute pain outcome measures: a validation study. J Pain Symptom Manage. 2003;25(5):406-411.

43. Dillmann U, Nilges P, Saile H, Gerbershagen HU. Behinderungseinschätzung bei chronischen Schmerzpatienten [Assessing disability in chronic pain patients]. Schmerz. 1994;8(2):100-110.

44. Cox D. Regression models and life tabels. J R Stat Soc B. 1972;34: $187-220$.
45. Cohen J. Statistical Power Analysis for the Behavioral Sciences New York: Academic Press; 1998.

46. Katz J, Seltzer Z. Transition from acute to chronic postsurgical pain: risk factors and protective factors. Expert Rev Neurother. 2009; 9(5):723-744.

47. Dai F, Belfer I, Schwartz CE, et al. Association of catechol-O-methyltransferase genetic variants with outcome in patients undergoing surgical treatment for lumbar degenerative disc disease. Spine J. 2010; 10(11):949-957.

48. Tegeder I, Costigan M, Griffin RS, et al. GTP cyclohydrolase and tetrahydrobiopterin regulate pain sensitivity and persistence. Nat Med. 2006;12(11):1269-1277.

49. Solovieva S, Leino-Arjas P, Saarela J, Luoma K, Raininko R, Riihimaki H. Possible association of interleukin 1 gene locus polymorphisms with low back pain. Pain. 2004;109(1-2):8-19.

50. Dominici R, Cattaneo M, Malferrari G, et al. Cloning and functional analysis of the allelic polymorphism in the transcription regulatory region of interleukin-1 alpha. Immunogenetics. 2002;54(2): 82-86

51. Diatchenko L, Slade GD, Nackley AG, et al. Genetic basis for individual variations in pain perception and the development of a chronic pain condition. Hum Mol Genet. 2005;14(1):135-143.

52. Doehring A, Kusener N, Fluhr K, Neddermeyer TJ, Schneider G, Lotsch J. Effect sizes in experimental pain produced by gender, genetic variants and sensitization procedures. PLoS One. 2011;6(3):e17724.

53. Lötsch J, Fluhr K, Neddermayer T, Doehring A, Geisslinger G. The consequence of concomitantly present functional genetic variants for the identification of functional genotype-phenotype associations in pain. Clin Pharmacol Ther. 2009;85(1):25-30.

54. Kim H, Neubert JK, San Miguel A, et al. Genetic influence on variability in human acute experimental pain sensitivity associated with gender, ethnicity and psychological temperament. Pain. 2004;109(3):488-496.

55. George SZ, Parr JJ, Wallace MR, et al. Biopsychosocial influence on exercise-induced injury: genetic and psychological combinations are predictive of shoulder pain phenotypes. J Pain. 2014;15(1):68-80.

56. George SZ, Hirsh AT. Psychologic influence on experimental pain sensitivity and clinical pain intensity for patients with shoulder pain. J Pain. 2009;10(3):293-299.

57. Kim H, Mittal DP, Iadarola MJ, Dionne RA. Genetic predictors for acute experimental cold and heat pain sensitivity in humans. $J$ Med Genet. 2006;43(8):e40.

58. Bachvarov DR, Landry M, Houle S, Pare P, Marceau F. Altered frequency of a promoter polymorphic allele of the kinin B1 receptor gene in inflammatory bowel disease. Gastroenterology. 1998;115(5):1045-1048.

59. Ferrero-Miliani L, Nielsen OH, Andersen PS, Girardin SE. Chronic inflammation: importance of NOD2 and NALP3 in interleukin-1beta generation. Clin Exp Immunol. 2007;147(2):227-235.

60. Diatchenko L, Nackley AG, Slade GD, et al. Catechol-O-methyltransferase gene polymorphisms are associated with multiple pain-evoking stimuli. Pain. 2006;125(3):216-224.

61. Zubieta JK, Heitzeg MM, Smith YR, et al. COMT val158met genotype affects mu-opioid neurotransmitter responses to a pain stressor. Science. 2003;299(5610):1240-1243.

62. Lötsch J, Belfer I, Kirchhof A, et al. Reliable screening for a painprotective haplotype in the GTP cyclohydrolase 1 gene $(\mathrm{GCH} 1)$ through the use of 3 or fewer single nucleotide polymorphisms. Clin Chem. 2007;53(6):1010-1015.

63. Bessler H, Shavit Y, Mayburd E, Smirnov G, Beilin B. Postoperative pain, morphine consumption, and genetic polymorphism of IL-1beta and IL-1 receptor antagonist. Neurosci Lett. 2006;404(1-2):154-158.

64. Guimaraes AL, de Sa AR, Victoria JM, de Fatima Correia-Silva J, Gomez MV, Gomez RS. Interleukin-1beta and serotonin transporter gene polymorphisms in burning mouth syndrome patients. J Pain. 2006;7(9):654-658.

65. Duerr RH, Taylor KD, Brant SR, et al. A genome-wide association study identifies IL23R as an inflammatory bowel disease gene. Science. 2006;314(5804):1461-1463. 
66. Rodriguez-Lopez J, Perez-Pampin E, Gomez-Reino JJ, Gonzalez A. Regulatory polymorphisms in extracellular matrix protease genes and susceptibility to rheumatoid arthritis: a case-control study. Arthritis Res Ther. 2006;8(1):R1.

67. Fillingim RB, Kaplan L, Staud R, et al. The A118G single nucleotide polymorphism of the mu-opioid receptor gene (OPRM1) is associated with pressure pain sensitivity in humans. J Pain. 2005;6(3):159-167.

68. Sugiura Y, Niimi T, Sato S, et al. Transforming growth factor betal gene polymorphism in rheumatoid arthritis. Ann Rheum Dis. 2002;61(9):826-828.
69. Park JJ, Lee J, Kim MA, Back SK, Hong SK, Na HS. Induction of total insensitivity to capsaicin and hypersensitivity to garlic extract in human by decreased expression of TRPV1. Neurosci Lett. 2007;411(2):87-91. 


\section{Supplementary materials}

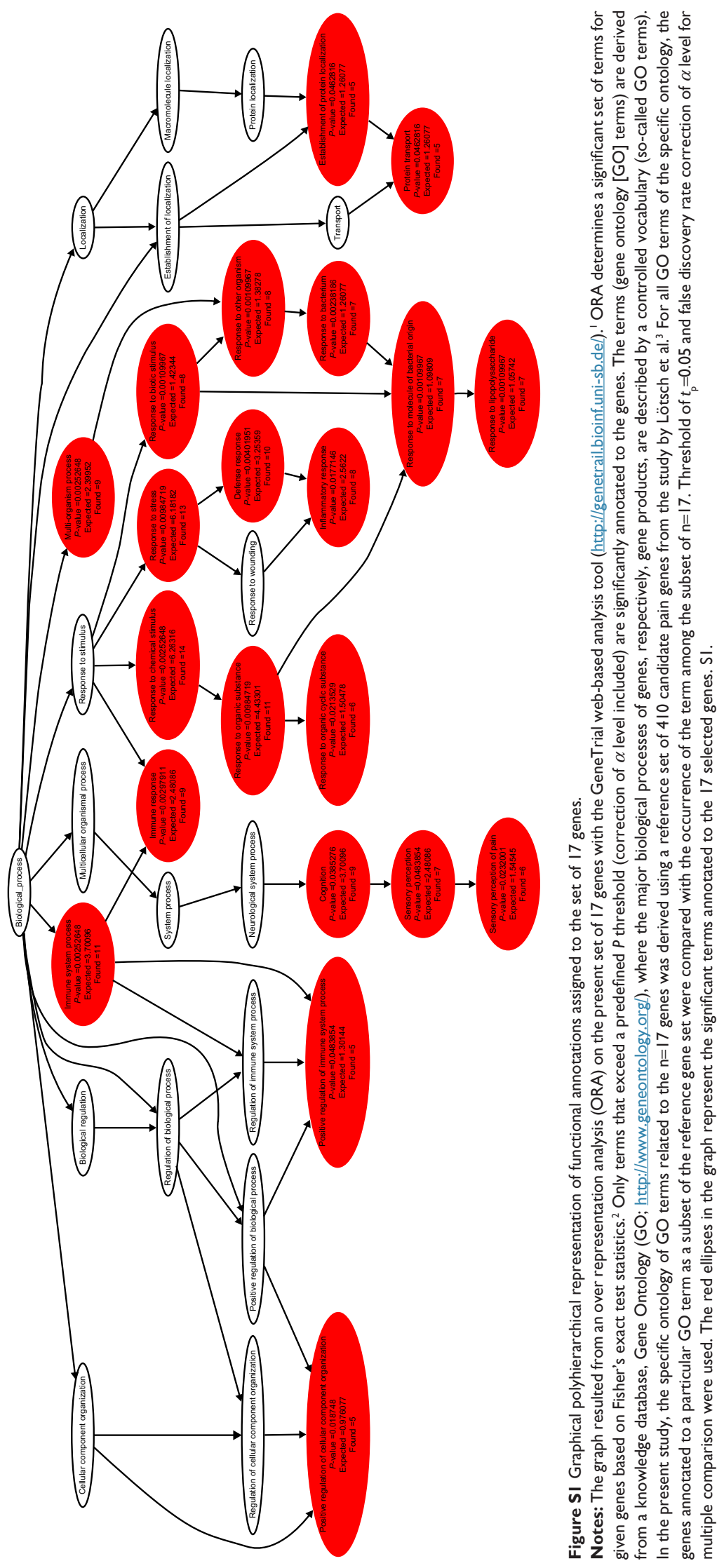


Table SI Significant GO term annotations for the $n=17$ genes

\begin{tabular}{|c|c|c|c|c|}
\hline GO terms & GO term ID & Nr expected genes & Nr observed genes & $P$-values (FDR) \\
\hline Response to molecule of bacterial origin & GO:0002237 & 1.09809 & 7 & 0.00109967 \\
\hline Response to biotic stimulus & GO:0009607 & 1.42344 & 8 & 0.00109967 \\
\hline Response to lipopolysaccharide & GO:0032496 & 1.05742 & 7 & 0.00109967 \\
\hline Response to other organism & GO:005I707 & 1.38278 & 8 & 0.00109967 \\
\hline Response to bacterium & GO:0009617 & 1.26077 & 7 & 0.00238186 \\
\hline Immune system process & GO:0002376 & 3.70096 & 11 & 0.00252648 \\
\hline Response to chemical stimulus & GO:0042221 & 6.26316 & 14 & 0.00252648 \\
\hline Multi-organism process & GO:005I704 & 2.39952 & 9 & 0.00252648 \\
\hline Immune response & GO:0006955 & 2.48086 & 9 & 0.00297911 \\
\hline Defense response & GO:0006952 & 3.25359 & 10 & $0.0040|95|$ \\
\hline Response to stress & GO:0006950 & 6.18182 & 13 & 0.00984719 \\
\hline Response to organic substance & GO:0010033 & 4.43301 & 11 & 0.00984719 \\
\hline Inflammatory response & GO:0006954 & 2.5622 & 8 & 0.0177146 \\
\hline Positive regulation of cellular component organization & GO:005II30 & 0.976077 & 5 & 0.018748 \\
\hline Response to organic cyclic substance & GO:00I4070 & 1.50478 & 6 & 0.0213529 \\
\hline Sensory perception of pain & GO:0019233 & I.54545 & 6 & 0.0232001 \\
\hline Cognition & GO:0050890 & 3.70096 & 9 & 0.0385276 \\
\hline Protein transport & GO:00I503I & 1.26077 & 5 & 0.0462816 \\
\hline Establishment of protein localization & GO:0045184 & 1.26077 & 5 & 0.0462816 \\
\hline Positive regulation of immune system process & GO:0002684 & 1.30144 & 5 & 0.0483854 \\
\hline Sensory perception & GO:0007600 & 2.48086 & 7 & 0.0483854 \\
\hline
\end{tabular}

Notes: The ORA analysis resulted in 2 I significant functional annotations (GO terms IDs and respective GO terms). The expected and observed number of genes for each term and the respective corrected $P$-value (FDR) are given. GO terms marked in bold represent the seven most annotated biological processes, in which the selected genes are involved.

Abbreviations: ORA, overrepresentation analysis; GO, gene ontology; $\mathrm{Nr}$, number; FDR, false discovery rate.

\section{References}

1. Keller A, Backes C, Al-Awadhi M, et al. GeneTrailExpress: a web-based pipeline for the statistical evaluation of microarray experiments. $B M C$ Bioinformatics. 2008;9:552.

2. Backes C, Keller A, Kuentzer J, et al. GeneTrail - advanced gene set enrichment analysis. Nucleic Acids Res. 2007;35(Web Server issue):W186-W192.
3. Lotsch J, Doehring A, Mogil JS, Arndt T, Geisslinger G, Ultsch A. Functional genomics of pain in analgesic drug development and therapy. Pharmacol Ther. 2013;139(1):60-70.
Journal of Pain Research

\section{Publish your work in this journal}

The Journal of Pain Research is an international, peer-reviewed, open access, online journal that welcomes laboratory and clinical findings in the fields of pain research and the prevention and management of pain. Original research, reviews, symposium reports, hypothesis formation and commentaries are all considered for publication.

\section{Dovepress}

The manuscript management system is completely online and includes a very quick and fair peer-review system, which is all easy to use. Visit http://www.dovepress.com/testimonials.php to read real quotes from published authors. 